\title{
Waterproof and Oil Repellent Treatments of Cotton Fabric
}

\author{
Md. Iusuf Khan ${ }^{1,2^{*}}$, Sheikh Sha Alam ${ }^{1}$, Fatema Jannat ${ }^{3,4}$, Md. Safiqul Islam ${ }^{1}$ \\ ${ }^{1}$ Department of Textile Engineering, Wuhan Textile University, Wuhan, China \\ ${ }^{2}$ Department of Textile Engineering, Port City Intentional University, Chittagong, Bangladesh \\ ${ }^{3}$ Department of Fashion Design and Technology, Port City International University, Chittagong, Bangladesh \\ ${ }^{4}$ Department of Textile Engineering, Port City Intentional University, Chittagong, Bangladesh \\ Email: *Iusufkhan50@gmail.com
}

How to cite this paper: Khan, Md.I., Alam, S.S., Jannat, F. and Islam, Md.S. (2020) Waterproof and Oil Repellent Treatments of Cotton Fabric. Journal of Textile Science and Technology, 6, 59-80.

https://doi.org/10.4236/jtst.2020.61006

Received: December 12, 2019

Accepted: February 23, 2020

Published: February 26, 2020

Copyright $\odot 2020$ by author(s) and Scientific Research Publishing Inc. This work is licensed under the Creative Commons Attribution International License (CC BY 4.0).

http://creativecommons.org/licenses/by/4.0/

(c) (i) Open Access

\begin{abstract}
The waterproof and oil-repellent finishing of the dyed single-sided plain cotton fabric was carried out by two-dip and two-pad process. The influences of baking temperature $\left({ }^{\circ} \mathrm{C}\right)$, baking time $(\mathrm{min})$, concentration of finishing solution $(\mathrm{g} / \mathrm{L})$ and percentage of liquid on waterproof effect of fabric were analyzed; the influences of the contact angle and the baking temperature $\left({ }^{\circ} \mathrm{C}\right)$, the baking time $(\mathrm{min})$ and the concentration of the finishing agent $(\mathrm{g} / \mathrm{L})$ on the oil repellency of the fabric were investigated. The results showed that the best water-repellent finishing technology for cotton fabric was the concentration of finishing agent $30 \mathrm{~g} / \mathrm{L}$, the baking temperature $110^{\circ} \mathrm{C}$, the baking time $1.5 \mathrm{~min}$ and the liquid-uptake $70 \%$. The best oil-repellent finishing process for cotton fabric is $35 \mathrm{~g} / \mathrm{L}$ for finishing agent, $150^{\circ} \mathrm{C}$ for baking temperature, and $1.5 \mathrm{~min}$ for baking time and pick up rate of $80 \%$. After cotton fabric is treated with water-repellent and oil-repellent agent, the water-repellent contact angle of the fabric can reach $128^{\circ}$ and the oil-repellent grade 6 . The best finishing effect is obtained at this time. After the finishing agent acts on the surface of the fibre, the surface properties of the fibre can be changed, and the surface of the fibre can be changed from hydrophilicity to hydrophobicity. The finishing agent has good film-forming property, which makes the surface of cotton fibre smooth and has good waterproof and oil-repellent performance.
\end{abstract}

\section{Keywords}

Cotton Fibre, Waterproof, Contact Angle, Orthogonal Experimental Design, Oil Repellent Treatment 


\section{Introduction}

Fabric can stay recycled to type clothing for people and numerous additional things. People often wear cotton clothes, especially in hot weather. Today's cotton stays the greatest recycled textile fibre in the establishment. Presently, the whole fibres used in clothing and domestic things ensure a marketplace share of $56 \%$ in the United States. An additional influence is attributed to nonwoven textiles and individual protection products. The initial indication of cotton use came since India, and the period given to fabrics was 3000BC [1]. Cotton fabrics of considerable age must also be established in different countries. Cotton planting began to spread from India to Egypt, China, and the South Pacific. Cotton is the source of the achieved plant, and that one is categorized as a usual material because this one is found starting sources of fibre, seed fibre short fibres, having a length of $10-65 \mathrm{~mm}$, and is whitened to light brown in its regular state-run [2], mainly collected from a material called fibre, which is called the king of all fibres. Fibres with long fibres are named "long fibres" because they are more used to make high-quality fabrics. Long fibres are particularly suitable because they are easy to spin and produce strong, smooth yarns [3].

Cotton fibre is the purest cellulose and is the maximum rich polymer in the environment. Approximately $91 \%$ of cotton fibres are cellulose. Most of the plants are composed of cellulose, however to changeable degrees. Bast fibre from plant stems, such as flax, jute, ramie, and kenaf, accounts for about three-quarters of cellulose [4]. Conifers and deciduous plants contain $41 \%-51 \%$ cellulose, though added plant classes or amounts comprise abundant fewer cellulose. Cotton fibres have the uppermost molecular load and highest structural order among all plant fibres, namely high crystallinity, orientation, and fibre. Cotton having such high levels and the best plentiful regular polymer structural order is not astonishingly considered to be the main fibre and biomass [5].

The chemical configuration of cotton characters and their physical relationships with cellulose combination, fibre increase, and dryness, by way of fit as additional compound and basic aspects (physical assets, dyeing plus finishing) are discussed. Cotton fibre compartments develop at four consistent but different stages of start, elongation, minor cell wall condensing and development besides drying [6]. Important progress and possessions of cotton fibres through key wall construction (elongation) and minor wall thickening (cellulose production) and throughout drying (change over as of moving to actual hydrogen attached structures) have been made. Cellulose structure is presented in Figure 1.

Cellulose is an important structural element of the cell wall of all photosynthesis plant life. Also, cellulose is dextran. The D-glucose units are connected in a $(1 \rightarrow 4)$ manner (Figure 1) [7]. Although the joining is different from starch and glycogen, it is a beta connection. Therefore, the relation is beta-glucosidic-linkage. This arrangement is not helical because the beta link limits the polysaccharide to a linear formula. In the structure of the cellulose-OH 


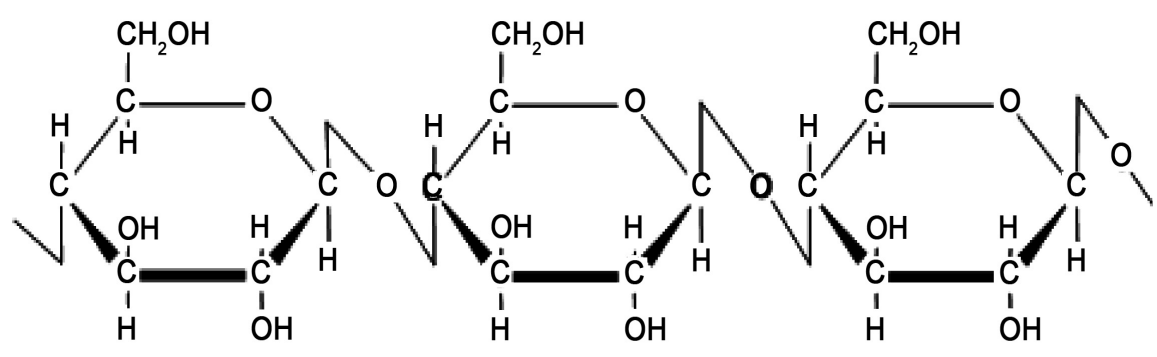

Figure 1. Cellulose structure.

group, it is directed to the outside of the chain structure [8]. Whenever the dual chains are nearby to each other, they tend to form a stack with each added due to hydrogen attachment among these hydroxyl groups. As an end result, a fibrous inexplicable building is suitable for the occupation of cellulose in the cell wall. Cotton knitted (S/J) dyed fabric was treated with a waterproof and oil repellent under different conditions and tested for its waterproof and oil repellency.

\section{Experiment and Methodology}

Cotton knitwear was treated with waterproof and oil repellent treatment under different conditions and tested for its waterproof and oil repellency. The experimental scheme was performed by orthogonal experiment design and the variables were the amount of finishing $(\mathrm{g} / \mathrm{L})$, the pick-up rate of (\%), the baking temperature $\left({ }^{\circ} \mathrm{C}\right)$ and the baking time $(\mathrm{min})$. It is necessary to test the waterproof and oil repellency of the sample and use the orthogonal design analysis to define the effect of various variables on the act of the cotton knitted (S/J) fabrics are analyzed and finally determine the optimized conditions.

\subsection{Materials}

$100 \%$ cotton knitted (bleached fabrics) were used for this experiment. The knitted fabrics were collected from the Chemistry and Chemical Engineering lab. The waterproof finishing RUNWELL TEO was taken directly from ECOIDEAL company, Ltd. (China) and the oil repellent finishing chemical DYMATIC INC was taken from RUDOLF CHEMIE Co., Ltd. (China). Reactive Orange 5 (Procion $\mathrm{H}$ ) dyes were profitable inferior bought from the Shanghai Jiaying Chemical Company (China). All the bleached fabrics, dyestuffs, basic chemicals etc. received from the Chemistry and Chemical Engineering examination center for Clean Production of Textile Dyeing and Printing, Ministry of Education lab. In this disquisition many more machineries were also used such as High Temperature and High-Pressure Dyeing Machine (HTX-12, Huaxia Technology Company, China) small dryer machine, small Padding Mangle (padder machine), Curing Machine, Washing Machine, K/S value test machine, Contact angle-KRÜSS easy drop Shape Analyzer-DSA, Oil repellent hydrocarbon test chemicals; n-Tetradecane (Cas number 629-59-4), n-Decane (Cas number 124-18-5) and 
n-Heptane (Cas number 142-82-5) was collected from Chemistry lab. Knit fabric has single jersey $(\mathrm{S} / \mathrm{J})$ structure with $145 \mathrm{~g} / \mathrm{m}^{2}$ was used in this study.

\subsubsection{Experimental Conditions}

It is essential to test the waterproof and oil repellency of the sample and use the orthogonal investigational scheme analysis to regulate the effect of various variables on the performance of the cotton knitted dyed fabrics are analyzed and finally determine the optimized conditions (waterproof and oil repellent treatment of cotton fabrics). Two optimized conditions for waterproof and oil repellent treatment are mixed together and to calculate the presentation of hydrophobicity on cotton knitted (S/J) dyed fabrics.

\subsubsection{Experimental Materials}

Cotton knitted dyed sample each consisting of 30 pieces and each sample weight $8.5 \mathrm{~g}$ (for waterproof treatment). On the other side, cotton knitted dyed sample each consisting of 25 pieces and the sample weight $3.97 \mathrm{~g}$ (For oil repellent treatment).

\subsubsection{Fabric Preparation}

Cotton knitted bleach fabric roll were collected from the chemical lab. To inspect the fabric cleanliness and to check the Crease mark, Lycra drop, Hole mark, GSM cut into many pieces as A4 size ( $8 \times 11$ inch). Thus, the fabric was prepared for the suitable following process like reactive dyeing.

\subsubsection{Experimental Equipment}

Scissors, Beakers, Dropper, Petridis, Glass rods, Electrical balances, Safety glass, Mask, Apron, Hand gloves, Padding machine, Small dryer machine, Curing machine, Washing machine, Easy drop test machine.

\subsection{Methodology}

Experimental method: Two dip two-pad process.

Cotton knitted dyed sample was sunk into a waterproof solution or oil repellent solution and passed through the padding machine roller. Then padded sample again put in waterproof solution and passed through the padding machine roller. This process is called two-dip two pad process.

\subsubsection{Flow Chart of Waterproof of Cotton Cloths}

Cotton knitted dyed sample $\rightarrow$ dosing (sunk into waterproof solution for two times) $\rightarrow$ padding (pass through the two times-Pick up rate of $80 \%) \rightarrow \operatorname{dry}\left(75^{\circ} \mathrm{C}\right.$ $\left.-80^{\circ} \mathrm{C}\right)$ normally $4-5 \mathrm{~min} \rightarrow$ baking temperature and time $\rightarrow$ washing $\left(60^{\circ} \mathrm{C} \times\right.$ $15 \mathrm{~min}) \rightarrow \operatorname{dry}\left(75^{\circ} \mathrm{C}-80^{\circ} \mathrm{C}\right)$ naturally $4-5 \mathrm{~min} \rightarrow$ contact angle measurement (Drop shape analyzer).

\subsubsection{Dyeing of Cotton Knitted Cloth through Reactive Dyes}

Cotton knitted bleach sample dyed with the C.I. Reactive 0 range 5. A4 size fa- 
bric sample was taken (total samples, 30). Dyeing Recipe of Cotton Fabrics, which are stated in Table 1.

\subsubsection{Reactive Dyeing Process}

Bleached fabric and reactive dyestuff (reactive orange 5) were added into a small dyeing pot at room temperature for $10 \mathrm{~min}$, then salt $(\mathrm{NaCl})$ was added for swelling the affinity. Subsequently the machine runs for $10 \mathrm{~min}$ and the temperature was increased up to $95^{\circ} \mathrm{C}$. When the dye batch reached the temperature at $95^{\circ} \mathrm{C}$, sodium carbonate $\left(\mathrm{Na}_{2} \mathrm{CO}_{3}\right)$ was added for fixation, run the dye bath were kept at $95^{\circ} \mathrm{C}$ for $30 \mathrm{~min}$. After that, the temperature was fallen on to $30^{\circ} \mathrm{C}$. Finally, the dye bath was dropped and carried on the after-treatment process, which is stated in Figure 2.

\subsubsection{Washing Process of Cotton Knitted Dyed Fabric}

To remove the regular impurities, residual auxiliaries, etc. and for better hue fastness afterward, behavior process is very essential. At first complete elimination of salts and alkali is required to perform by rinsing and then it needs soap wash to confirm the complete recovery from unfixed dyes. Finally, the dyed sample was dried at $75^{\circ} \mathrm{C}-80^{\circ} \mathrm{C}$. Wash recipe of cotton knitted dyed sample, which is stated in Table 2.

\subsection{Color Strength}

To estimate dyeing performance, the color strength $(K / S)$ and CIELAB of the cotton knitted dyed samples were investigated using a Data color 400 spectro-photometer through illuminant $\mathrm{D} 65$ and $10^{\circ}$ observer. The $K / S$ value is calculated by the Kubelka-Munk Equation, $K / S=(1-R)^{2} / 2 R$, where $R$ is the reflectance, $K$ is the immersion co-efficient, and $S$ is the sprinkle coefficient [9].

Table 1. Dyeing formula of cotton fabrics.

\begin{tabular}{cc}
\hline Dye mass (o.m.f) & $2 \%$ \\
Salt $(\mathrm{NaCl})$ & $40 \mathrm{~g} / \mathrm{L}$ \\
$\mathrm{Na}_{2} \mathrm{CO}_{3}:$ & $10 \mathrm{~g} / \mathrm{L}$ \\
Temperature & $95^{\circ} \mathrm{C}$ \\
Time & $60 \mathrm{~min}$ \\
Liquor ratio & $1: 20$ \\
\hline
\end{tabular}

Table 2. Wash recipe of cotton knitted dyed fabrics.

\begin{tabular}{cc}
\hline Detergent & $2 \mathrm{~g} / \mathrm{L}$ \\
$\mathrm{M}: \mathrm{L}$ & $1: 20$ \\
Temperature & $95^{\circ} \mathrm{C}$ \\
Time & $15 \mathrm{~min}$ \\
\hline
\end{tabular}




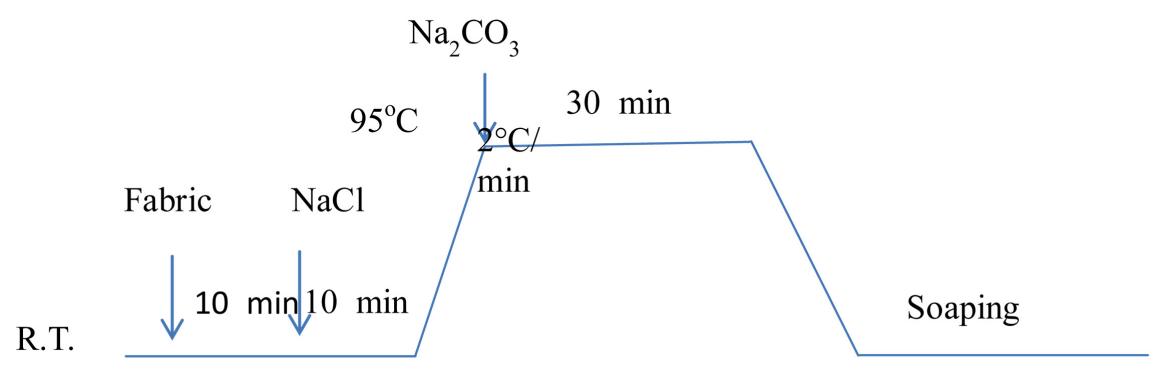

Figure 2. Reactive dyeing curve of the cotton fabric.

The color variation is expressed as $\Delta E^{*}$ and is designed by Equation (1).

$$
\Delta E^{*}=\sqrt{\left(\Delta L^{*}\right)^{2}+\left(\Delta a^{*}\right)^{2}+\left(\Delta b^{*}\right)^{2}}
$$

where $\Delta E^{*}$ is the CIELAB color variance amongst batch over standard. Now $\Delta L^{*}, \Delta a^{*}, \Delta b^{*}$ and hence $\Delta E^{*}$ remain in proportionate parts. $\Delta L^{*}$ signifies the difference among lightness (where $L^{*}=100$ ) then darkness (where $L^{*}=0$ ), $\Delta a^{*}$ the difference between red $\left(+a^{*}\right)$ and green $\left(-a^{*}\right)$ and $\Delta b^{*}$ the difference between yellow $\left(+b^{\star}\right)$ and blue $\left(-b^{\star}\right)$. For the study, the amount of levelness was defined according to $\Delta E$ [10]. All samples indicated a maximum absorption wavelength value $\left(\lambda_{\max }\right)$ at $444 \mathrm{~nm}$. The $\Delta E$ value is also an essential parameter in the dyeing procedure, which can indicate the amount of levelness of dyed cloth.These cloths present a $0^{\circ}$ contact angle through water, as the drops were immersed instantly presenting outstanding hydrophilic characters of cotton knitted dyed fabrics [11]. Collected fabrics were first dyed and processed with waterproof finishing chemicals (RUNWELL TEO) and also oil repellent finishing chemical RUDOLF CHEMIE (DYMATIC INC) in different concentrations, different backing temperature, different backing time and also different pick-up rate ratio. The application of waterproof finishing and oil repellent treatment of cotton is to change their properties from hydrophilic to hydrophobic.

\subsection{Waterproof Finishing}

The waterproof chemical (RUNWELL TEO) has been applied on cotton knitted dyed fabric to increase the hydrophobic properties on both fabric surface. Waterproof chemical RUNWELL TEO was mixed with distilled water at different concentration ( $1 \mathrm{~g} / \mathrm{L}, 10 \mathrm{~g} / \mathrm{L}, 20 \mathrm{~g} / \mathrm{L}, 30 \mathrm{~g} / \mathrm{L}, 40 \mathrm{~g} / \mathrm{L}, 50 \mathrm{~g} / \mathrm{L}, 70 \mathrm{~g} / \mathrm{L}$ and $90 \mathrm{~g} / \mathrm{L})$ to maintain the proper $\mathrm{pH}$ range $5-6$. Then the cotton knitted dyed sample was sunk into a waterproof solution and passed through the padding machine roller. Then padded sample again put in waterproof solution and passed through the padding machine roller. This process is called two-dip two pad process. The pick-up rate of $80 \%$ was intended by Equation (2).

$$
\text { Pick-up rate } \%=\frac{\text { After Fabric Weight }- \text { Before Fabric Weight }}{\text { Before Fabric Weight }} \times 100 \%
$$

Then the double padded sample was preserved in small dryer machine at $70^{\circ} \mathrm{C}-75^{\circ} \mathrm{C}$ for $4-5 \mathrm{~min}$. subsequently drying, the sample was reserved at dif- 
ferent backing time ( $0.5 \mathrm{~min}, 1 \mathrm{~min}, 1.5 \mathrm{~min}, 2 \mathrm{~min}, 2.5 \mathrm{~min}$ ) and temperature $\left(110^{\circ} \mathrm{C}, 120^{\circ} \mathrm{C}, 130^{\circ} \mathrm{C}, 150^{\circ} \mathrm{C}\right.$, and $\left.170^{\circ} \mathrm{C}\right)$. To remove the impurities and it needs soap wash of cotton fabric (waterproof) which are stated in Table 3.

The sample was rinsed with cold water then dried in an oven at $75^{\circ} \mathrm{C}-80^{\circ} \mathrm{C}$ for 4 - $5 \mathrm{~min}$. The main focus of this thesis to investigate optimized condition for waterproof finishing chemical (RUNWELL TEO).

The detail information of the treatment is described below.

\section{1) Waterproof application bath (group 1)}

Cotton knitted dyed cloths were treated with RUNWELL TEO waterproof finishing concentration is $30 \mathrm{~g} / \mathrm{L}$ solution was prepared. Pad-mangle machine (pick-up rate $80 \%$ and padder pressure $0.5\left(\mathrm{~kg} / \mathrm{cm}^{2}\right)$ was recycled for padding respectively and oven instrument was used for proper drying. After drying, the sample was taken for curing at a different curing temperature of $110^{\circ} \mathrm{C}, 120^{\circ} \mathrm{C}$, $130^{\circ} \mathrm{C}, 150^{\circ} \mathrm{C}$, and $170^{\circ} \mathrm{C}$ individually. Now, the backing time was $2 \mathrm{~min}$ on every step. The sample was washed away at $60^{\circ} \mathrm{C}$ for $15 \mathrm{~min}$. Contact (position) angle of every sample was determined very carefully to identify the suitable backing temperature.

\section{2) Waterproof application bath (group 2)}

Waterproof chemicals RUNWELL TEO the concentrations are $30 \mathrm{~g} / \mathrm{L}$, suitable backing temperature $130^{\circ} \mathrm{C}$. Pad-mangle machine (pick-up rate $80 \%$ ) was recycled for padding respectively and to change the baking time is configured as follows: $0.5 \mathrm{~min}, 1 \mathrm{~min}, 1.5 \mathrm{~min}, 2 \mathrm{~min}$, and $2.5 \mathrm{~min}$ respectively. The sample was washed away at $60^{\circ} \mathrm{C}$ for $15 \mathrm{~min}$. The contact angle of every sample was determined very carefully to identify the suitable backing time.

\section{3) Waterproof application bath (group 3)}

To change the concentration of waterproof chemical respectively $(1 \mathrm{~g} / \mathrm{L}, 10$ $\mathrm{g} / \mathrm{L}, 20 \mathrm{~g} / \mathrm{L}, 30 \mathrm{~g} / \mathrm{L}, 40 \mathrm{~g} / \mathrm{L}, 50 \mathrm{~g} / \mathrm{L}, 70 \mathrm{~g} / \mathrm{L}$ and $90 \mathrm{~g} / \mathrm{L}$ ) from a separate bath were taken with standard bath condition. Waterproof finishing chemicals were prepared. Pad-mangle machine (pick-up rate $80 \%$ ) was recycled for padding respectively and oven instrument was used for proper drying. After drying the sample was taken for curing at curing temperature of $130^{\circ} \mathrm{C}$ individually. At this point, the backing time was $2 \mathrm{~min}$ on every step. The sample was washed away at $60^{\circ} \mathrm{C}$ for $15 \mathrm{~min}$. The contact angle of every cotton sample was determined very carefully to identify the suitable concentration.

4) Variable pick up rate (group 4)

Waterproof suitable concentrations, curing temperature and curing time as RUNWELL TEO are configured as follows $30 \mathrm{~g} / \mathrm{L}, 130^{\circ} \mathrm{C}, 2$ minutes. To change

Table 3. Soap wash of cotton fabric (waterproof).

\begin{tabular}{cc}
\hline Detergent & $2 \mathrm{~g} / \mathrm{L}$ \\
$\mathrm{M}: \mathrm{L}$ & $1: 20$ \\
Temperature & $60^{\circ} \mathrm{C}$ \\
Time & $15 \mathrm{~min}$ \\
\hline
\end{tabular}


the pick-up rate of $\%$ i.e. $70 \%, 75 \%, 80 \%, 85 \%, 90 \%$ respectively. The contact angle of every sample was determined very carefully to identify the suitable pick-up rate of \%. Waterproof finishing suitable condition (three levels-four factors) such as Concentration $(\mathrm{g} / \mathrm{L})$, Temperature $\left({ }^{\circ} \mathrm{C}\right)$, Time $(\mathrm{min})$ and pick up rate of (\%) are included in the orthogonal experimental scheme. To catch out the best waterproof optimized result.

\subsection{Flow Chart of Oil Repellent Cotton Cloths}

Cotton knitted dyed sample $\rightarrow$ dosing (sunk into oil repellent DYMATIC INC solution for two times ) $\rightarrow$ padding (pass through the two times-Pick up rate of $80 \%) \rightarrow \operatorname{dry}\left(75^{\circ} \mathrm{C}-80^{\circ} \mathrm{C}\right)$ normally $4-5 \mathrm{~min} \rightarrow$ baking temperature and time $\rightarrow$ washing $\left(60^{\circ} \mathrm{C} \times 15 \mathrm{~min}\right) \rightarrow \operatorname{dry}\left(75^{\circ} \mathrm{C}-80^{\circ} \mathrm{C}\right)$ naturally $4-5 \mathrm{~min} \rightarrow$ hydrocarbon test (n-Tetradecane/n-Decane/n-Heptane).

\section{Oil Repellent Treatment}

The oil repellent finishing RUDOLF CHEMIE (DYMATIC INC) has been applied on cotton knitted dyed fabric to increase the oil repellency properties of cotton fabrics. Cotton fabric is hydrophilic in nature but after oil repellent treatment on dyed fabric becomes hydrophobic. Oil repellent (DYMATIC INC) was mixed with distilled water at different concentration $(20 \mathrm{~g} / \mathrm{L}, 25 \mathrm{~g} / \mathrm{L}, 30 \mathrm{~g} / \mathrm{L}$, $35 \mathrm{~g} / \mathrm{L}, 40 \mathrm{~g} / \mathrm{L}, 45 \mathrm{~g} / \mathrm{L}$ ) to maintain the proper $\mathrm{pH}$ range 2 - 5. Then the cotton knitted dyed sample was sunk into the oil repellent solution and passed through the padding machine roller. Then padded sample again put in oil repellent finishing chemical solution and also passed through the padding machine roller. Here pick up rate was $80 \%$ and the pressure was kept at 0.5 bar. Then the double padded (oil repellent) sample was kept as small dryer machine at $70^{\circ} \mathrm{C}-75^{\circ} \mathrm{C}$ for 4 - 5 min. Subsequently drying, the samples keep retained as different baking temperature $\left(130^{\circ} \mathrm{C}, 135^{\circ} \mathrm{C}, 140^{\circ} \mathrm{C}, 145^{\circ} \mathrm{C}, 150^{\circ} \mathrm{C}\right)$ and time $(0.5 \mathrm{~min}, 1 \mathrm{~min}, 1.5$ $\mathrm{min}, 2 \mathrm{~min}, 2.5 \mathrm{~min}$ ). To remove the impurities and it needs soap wash of cotton fabric (oil repellent) which are stated in Table 4.

The dyed sample was washed away with cold water then dry in a small dryer machine at $75^{\circ} \mathrm{C}-80^{\circ} \mathrm{C}$ for $4-5 \mathrm{~min}$. The main focus of this thesis is to catch out the optimized condition for oil repellent finishing chemical RUDOLF CHEMIE (DYMATIC INC).

The detail information of the treatment is described below.

1) Oil repellent application bath (group 1)

Cotton knitted dyed fabrics were treated with DYMATIC INC (RUDOLF

Table 4. Soap wash of cotton fabric (oil repellent).

\begin{tabular}{cc}
\hline Detergent & $2 \mathrm{~g} / \mathrm{L}$ \\
$\mathrm{M}: \mathrm{L}$ & $1: 20$ \\
Temperature & $60^{\circ} \mathrm{C}$ \\
Time & $15 \mathrm{~min}$
\end{tabular}


CHEMIE) oil repellent finishing chemicals at concentration is $30 \mathrm{~g} / \mathrm{L}$ solution was prepared. Pad-mangle machine (pick-up rate $80 \%$ and padder pressure 0.5 $\left(\mathrm{kg} / \mathrm{cm}^{2}\right)$ was recycled aimed at padding respectively and oven instrument was used for proper drying. Subsequently drying the sample was taken for different backing temperature are configured as follows: $130^{\circ} \mathrm{C}, 135^{\circ} \mathrm{C}, 140^{\circ} \mathrm{C}, 145^{\circ} \mathrm{C}$, $150^{\circ} \mathrm{C}$ individually. Here, the backing time was $1.5 \mathrm{~min}$ on every step. The sample was washed away at $60^{\circ} \mathrm{C}$ for $15 \mathrm{~min}$. Hydrocarbon test of every sample was determined very carefully to identify the suitable backing temperature and oil repellency grade.

\section{2) Oil repellent application bath (group 2)}

Oil repellent chemicals DYMATIC INC (RUDOLF CHEMIE) the concentrations is $30 \mathrm{~g} / \mathrm{L}$ were taken with standard bath condition. Oil repellent finishing solutions were prepared. Pad-mangle machine (pick-up rate $80 \%$ and padder pressure $0.5 \mathrm{~kg} / \mathrm{cm}^{2}$ ) was recycled for padding respectively and oven instrument was used for proper drying. Suitable backing temperature is $140^{\circ} \mathrm{C}$. Pad-mangle machine (pick-up rate was $80 \%$ ) was recycled for padding respectively and to change the baking time are configured as follows: $0.5 \mathrm{~min}, 1 \mathrm{~min}, 1.5 \mathrm{~min}, 2 \mathrm{~min}$, $2.5 \mathrm{~min}$ respectively. The sample was washed away at $60^{\circ} \mathrm{C}$ for $15 \mathrm{~min}$. Hydrocarbon test of every sample was determined very carefully to detect the suitable backing time and oil repellency grade.

\section{3) Oil repellent application bath (group 3)}

To change the concentration of oil repellent finishing respectively $20 \mathrm{~g} / \mathrm{L}, 25$ $\mathrm{g} / \mathrm{L}, 30 \mathrm{~g} / \mathrm{L}, 35 \mathrm{~g} / \mathrm{L}, 40 \mathrm{~g} / \mathrm{L}, 45 \mathrm{~g} / \mathrm{L}$ from a separate bath were taken with standard bath condition. Oil repellent finishing solution was prepared. Pad-mangle machine (pick-up rate $80 \%$ and padder pressure $0.5 \mathrm{~kg} / \mathrm{cm}^{2}$ ) was recycled for padding respectively and oven instrument was used for proper drying. After drying, the sample was taken for curing at curing temperature of $140^{\circ} \mathrm{C}$ individually. Now, the backing time was 2 min on every step. The sample was washed away at $60^{\circ} \mathrm{C}$ for 15 minutes. Hydrocarbon test of every sample was determined very carefully to detect the suitable concentration and oil repellency grade. Oil repellent finishing (three level-three factors) such as Concentration (g/L), Temperature $\left({ }^{\circ} \mathrm{C}\right)$, and Time (min) are included in the orthogonal experimental design. To catch out the oil repellent optimized condition.

\section{Results and Discussion}

\subsection{K/S Value Test}

Color intensity always defines the ability of a dye or pigment to change the color of a colorless material. The lower the concentration of the colored pigment required to achieve a determined color impression of a given hue depth, the greater the color intensity of the colored pigment. It depends on the absorption coefficient $(K)$ of the colorant. The higher the absorption coefficient, the higher the intensity of the colorant. The strength of several colorants (dye/pigment) is related to the absorption properties, which are stated in Table 5 and Table 6. 
Table 5. $K / S$ assessment of cotton cloth before treated (without waterproof finishing).

\begin{tabular}{cccccc}
\hline Test mode & $L^{*}$ & $a^{*}$ & $b^{*}$ & $\Delta E^{*}$ & $K / S$ value $(520 \mathrm{~nm})$ \\
\hline Sample 1 & 54.53467 & 46.55067 & 23.381 & 2.814667 & 5.53 \\
Sample 2 & 56.07533 & 45.98267 & 24.735 & 4.829333 & 5.22 \\
Sample 3 & 55.18067 & 46.454 & 24.340 & 3.928667 & 5.46 \\
\hline
\end{tabular}

Table 6. $K / S$ assessment of cotton cloth after treated (waterproof finishing).

\begin{tabular}{cccccc}
\hline Test mode & $L^{*}$ & $a^{*}$ & $b^{*}$ & $\Delta E^{*}$ & $K / S$ value $(520 \mathrm{~nm})$ \\
\hline Sample 1 & 55.43 & 47.27 & 23.661 & 2.868 & 5.57 \\
Sample 2 & 55.284 & 47.174 & 23.853 & 3.291 & 5.65 \\
Sample 3 & 55.744 & 45.594 & 24.294 & 5.466 & 5.44 \\
\hline
\end{tabular}

\section{Evaluating $\mathrm{K} / \mathrm{S}$ Value}

$L^{*}$ indicates the lightness, 0 being a perfect dark in addition to 100 a perfect white. Positive value $a^{*+}$ specifies the redness (R) and a negative value $a^{*-}$ indicates the greenness $(\mathrm{G})$, and also positive value $b^{*+}$ indicates the yellowness $(\mathrm{Y})$ and negative $b^{\star-}$ indicated the blueness (B). Values of $a^{\star}$ shown in Table 5 and Table 6 indicate that all samples are green. The $b^{\star}$ value indicates that the sample is bluer. The $L$ value indicates that the sample has a bright hue. From Table 5 and Table 6 , in the case where the same dye hue (2\%) and $a^{*}, b^{\star}, \Delta E^{\star} a b$ are almost unchanged, the variance in the waterproof concentration does not affect the hue. This value changes when the concentration of the waterproof finishing increases from zero to $2 \%$. That means, there is no obvious contrast chromatic aberration before and after treatment. Therefore, the waterproof treatment of the cotton fabric has no influence on the color of the cotton knitted (S/J) dyed fabrics.

\subsection{Control of Contact Angles}

Control of the wetting contact angle can generally be accomplished by depositing or bonding various organic and inorganic molecules onto the surface. This is typically accomplished by using a specialty silane chemical that forms a SAM (self-assembled monolayer) layer [12]. The statement of these specialty silanes can be completed in the gas stage by using a dedicated vacuum oven or liquid stage process. Particles that can bind extra perfluorinated ends to the surface can reduce surface energy (high water contact angle).

\subsubsection{Contact angle Test Measurement}

A goniometer is recycled to amount the contact angle amongst water droplets and the surface of the fabric. The consequences are dignified and verified digitally. A fresh syringe is complete with purified water and riding on a component that applies compression on the needle to the announcement a water drop at a period. This association helps to apply a continuous force for a constant stage to avoid any deviation. The name of the instrument KRÜSS easy drop Shape ana- 
lyzer-(DSA) and software was DSA 20 [13]. This was a video-based contact angle-determining scheme. The software was recycled to control and record the grades, at first samples were cut along wales and course wise direction with $(3 \times$ 3) $\mathrm{cm}^{2}$ measurement. Then the individual sample was placed on the base plate of Drop Shape analyzer in a proper way so that lens can focus the sample. Then software was ready for opening. A monitor at first Drop Shape analyzer Software "Open" was selected, then "Option" was selected. Then "Subtype" and afterward "Normal", "Icon Select" was selected and finally "Open FG Windows" was selected as a final step. By the software, the syringe was "pressed" until it free the water drop. This procedure was checked on the computer monitor. The picture in which the $\mathrm{H}_{2} \mathrm{O}$ droplet was maximum stable was selected for investigation. The DSA 20 software then considered the contact angle in that exact instance by sketch an arc over the droplet. Automatically an image of that water drop on the cloth surface was captured. Thus for every sample individual picture was generated. From those pictures, the contact angle was determined from the intersecting point between fabric and water by geometrical protractor. This technique was frequent for every individual sample. All the experimental waterproof contact angle degrees are put into the analysis of the waterproof experimental results and discussion.

\subsubsection{Principal of Waterproof and Oil Repellent Treatment}

The key element of cotton fibre is cellulose, which has good hydrophilic property, is easily wetted by water, and easily stained by oil. In order to make the cloth have certain waterproof and oil repellency, the cloth is subjected to waterproof and oil repellent finishing. A finishing chemical with a special molecular structure is useful to the cloth to change the composition of the surface layer of the strength so that the cloth is not wetted by water and common oils. The finishing agent has the function of changing the surface properties of the fibre, so that the surface of the fibre changes from hydrophilic to hydrophobic.

\subsection{Waterproof Finishing}

\subsubsection{Influence of Different Backing Temperature on Cotton Fabric}

The influence of baking temperature on waterproof (RUNWELL TEO) finishing concentration is $30 \mathrm{~g} / \mathrm{L}$, backing time is $2 \mathrm{~min}$; Pick up rate of $80 \%$, changing the baking temperature, finishing of cotton cloth according to the finishing process, which is stated in Figure 3 and Figure 4.

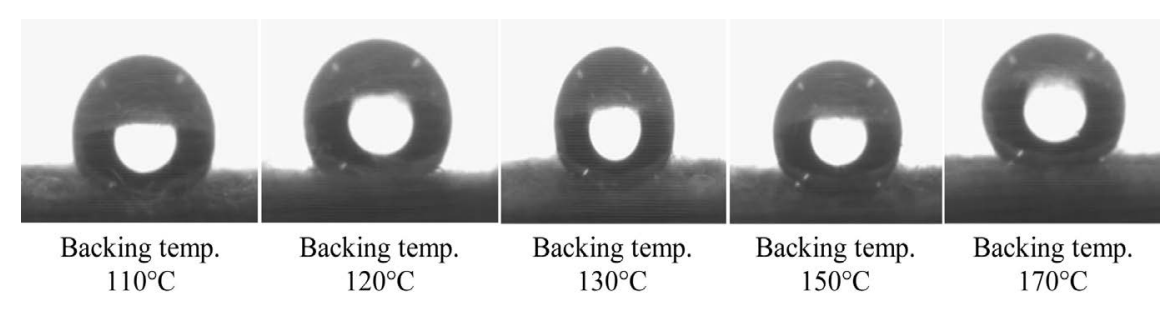

Figure 3. Images of the different backing temperature of waterproof treatment of cotton cloth. 


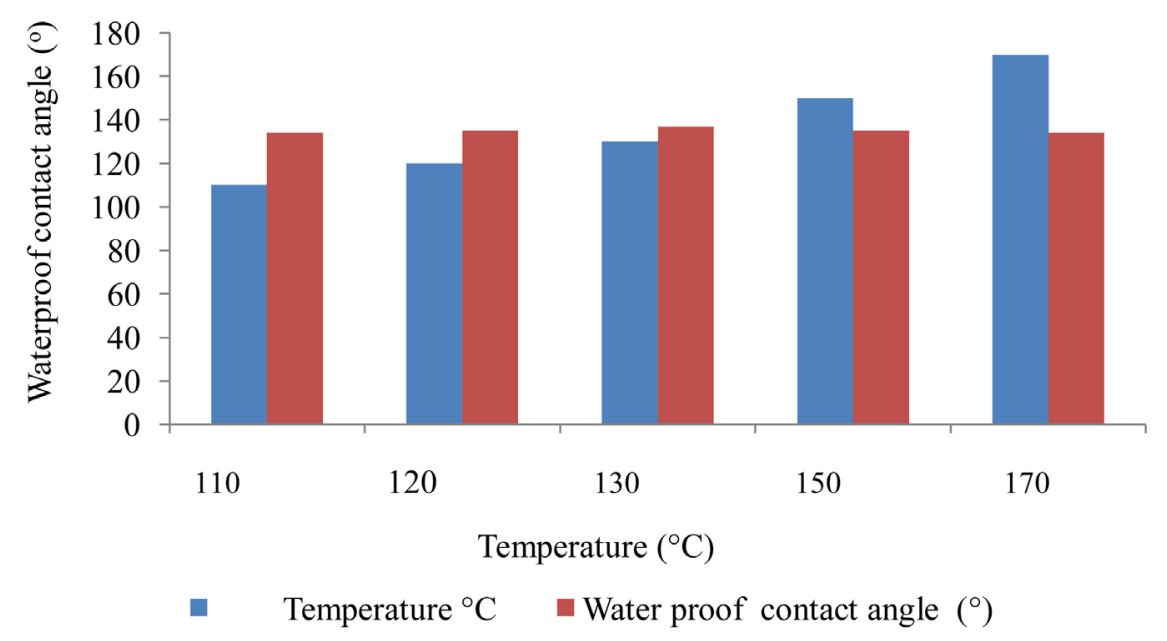

Figure 4. A graphical demonstration of the influence of baking temperature on waterproof treated fabric and contact angle $\left(^{\circ}\right)$.

According to Figure 4, when the baking temperature is $110^{\circ} \mathrm{C}-170^{\circ} \mathrm{C}$, the waterproof contact angle of the cotton fabric after finishing is about $137^{\circ}$. Considering the excessive baking temperature, the fabric is yellowed, the fibre is damaged. Therefore, the backing temperature has been taken into consideration. This backing temperature is $130^{\circ} \mathrm{C}$ the suitable backing temperature. For this suitable backing, temperature is $130^{\circ} \mathrm{C}$ we got contact angle of $137^{\circ}$.

\subsubsection{Influence of Different Backing Time on Cotton Fabric}

Effect of baking time on waterproof (RUNWELL TEO) finishing of cotton fabric $30 \mathrm{~g} / \mathrm{L}$, baking temperature is $130^{\circ} \mathrm{C}$, pick-up rate of $80 \%$, changing the baking time, finishing of cotton cloth according to the finishing process, which is clearly evident from in Figure 5 and Figure 6.

The grade of polymerization or film formation of the fluoro finish on the fabric is directly affected by the baking time. The baking time is too short, the polymerization or crosslinking of the organic fluoride is insufficient and the baking time is not too long crosslinking of the organic fluoride will be sufficient. The situation can be realized from Figure 6 that, as the baking time is extended, the waterproof contact angle of the cotton fabric after finishing is first increased and then decreased. When the baking time is at $2.5 \mathrm{~min}$, the water contact angle of the cotton cloth after finishing was significantly reduced. When the baking time was $2 \mathrm{~min}$, the waterproof contact angle of the cotton fabric after finishing was the largest, and the waterproof finishing effect was good. Therefore, the preferred baking time of the cotton fabric for waterproof finishing is $2 \mathrm{~min}$.

\subsubsection{Influence of Different Concentration on Cotton Fabric}

The influence of waterproof finishing (RUNWELL TEO) concentration on the cotton knitted dyed fabrics waterproof finishing effect of the fabric. When the baking temperature is $130^{\circ} \mathrm{C}$, and the baking time is 2 min, pick-up rate of $80 \%$, the concentration of the finishing is changed, and the cotton cloth is finished 


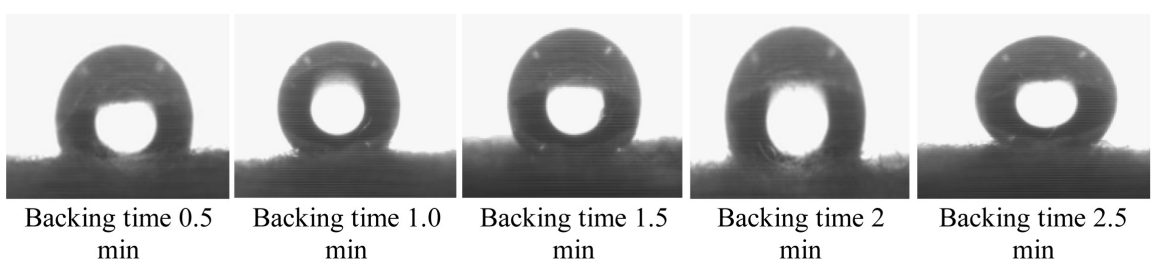

Figure 5. Images of different backing time of waterproof treatment of cotton cloths.

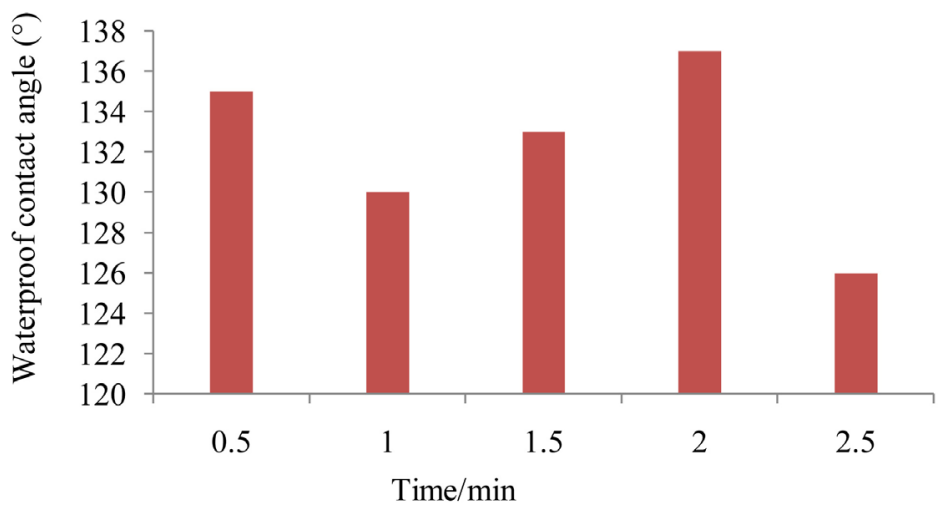

Figure 6. A graphical demonstration of the effect of different baking time on waterproof treatment fabrics and contact angle $\left({ }^{\circ}\right)$.

according to the finishing process, which is stated in Figure 7 and Figure 8.

The waterproof of the fabric is achieved by a layer of material with little surface energy adsorbed on the surface of the fabric. The effective component in the finishing liquid is an organic fluorine compound and the arrangement of the organic fluorine particles on the surface of the fibre reduces the surface tension of the fibre, thereby imparting a waterproof effect to the fabric.

Therefore, the content of organic fluorine in the finishing liquid determines whether the organic fluorine molecules on the surface (surface) of the fibre can be closely aligned, that is, the concentration of the finishing liquid can affect the waterproof of the cloth subsequently finishing.

This can be realized from Figure 8 that, when the finishing concentration is $1 \mathrm{~g} / \mathrm{L}$ the waterproof contact angle of the cloth is zero (completely wetting). When measuring, the water droplets will be on the surface of the finished cotton cloth in a short time, completely spread. To increase of the concentration of the finishing liquid, the waterproof contact angle of the cotton fabric after finishing has a tendency to increase suddenly then after certain point it starts decreasing. Therefore, the preferred waterproof concentration of the cotton cloth for waterproof finishing $30 \mathrm{~g} / \mathrm{L}$ because of the higher value of the contact angle.

\subsubsection{Influence of Variable Pick Up Rate of $\%$ on Cotton Fabric}

The effect of waterproof finishing pick up rate of $\%$ on the cotton knitted dyed fabrics waterproof finishing effect of the fabric. When the baking temperature was $130^{\circ} \mathrm{C}$, and the baking time was $2 \mathrm{~min}$, the concentration of the finishing 


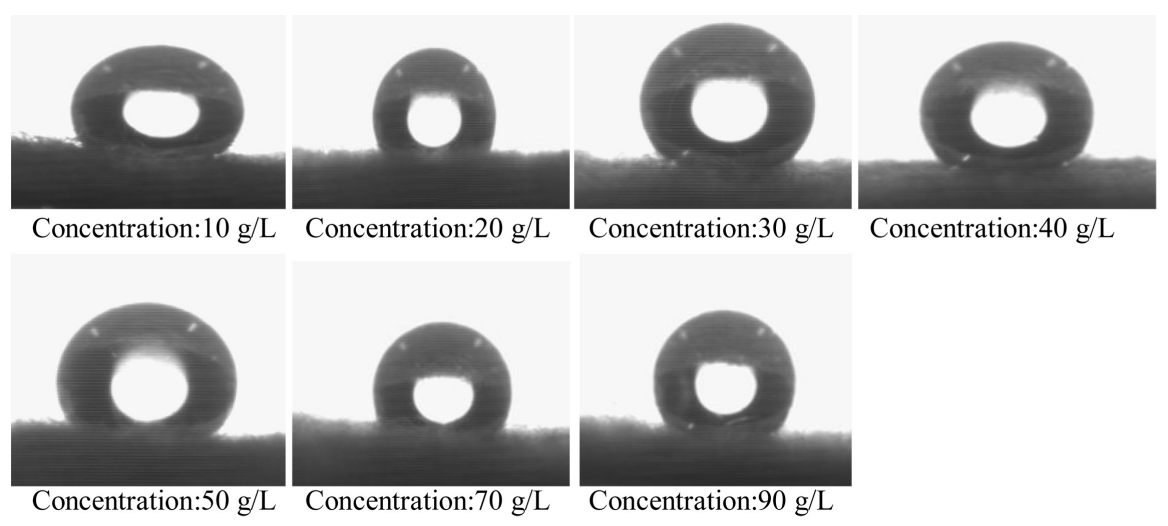

Figure 7. Image of different concentration of waterproof treatment of cotton cloth.

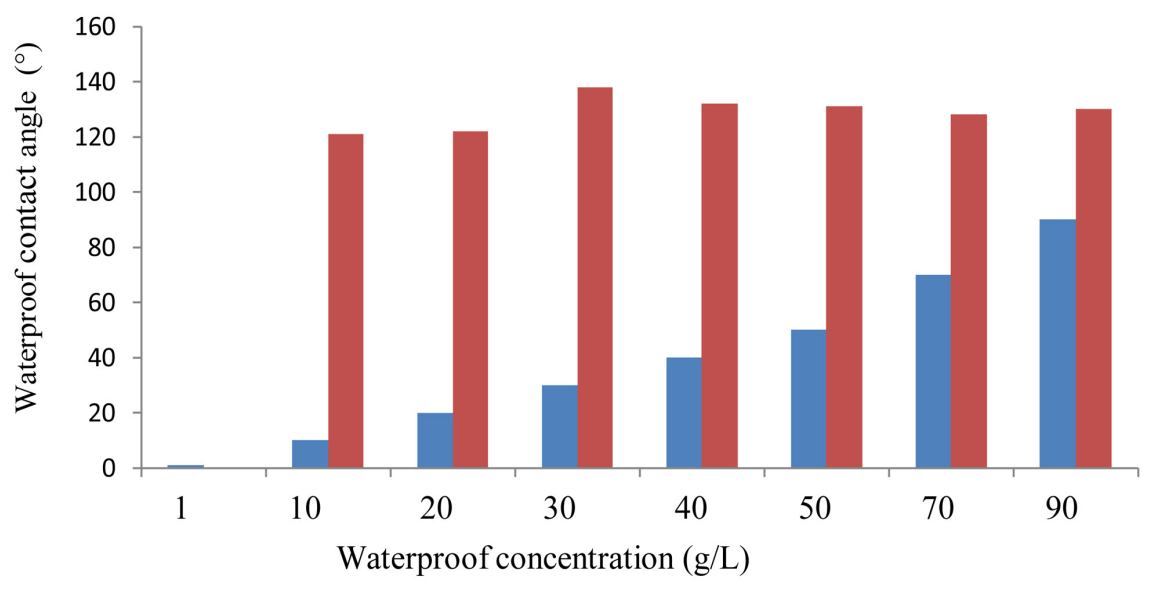

Water proof finishing concentration $(\mathrm{g} / \mathrm{L}) \quad$ Water proof contact angle $\left(^{\circ}\right)$

Figure 8. A Graphical demonstration of the effect of finishing chemical concentration $(\mathrm{g} / \mathrm{L})$ on waterproof cotton fabrics and contact angle $\left({ }^{\circ}\right)$.

solution $30 \mathrm{~g} / \mathrm{L}$, changing the pick-up rate of $\%$ and the cotton cloth is finished according to the finishing process, which is stated in Figure 9 and Figure 10.

This can be realized from Figure 10 that, with the gradual increment of pick-up rate \%, the waterproof contact angle of the cotton cloth after finishing show a little upward and downward movement i.e. for the first two pick up $\%$ contact angle increased and then we found a suitable parameter of 127 degrees at $80 \%$ pick up, but suddenly after this pick up rate decreased a little bit. Therefore, the preferred pick up-rate of $\%$ of cotton fabric for waterproof finishing is $80 \%$ due to the higher contact angle value.

Therefore all the preferred backing temperature is $130^{\circ} \mathrm{C}$, backing time is 2 min, the concentration of waterproof finishing solution $30 \mathrm{~g} / \mathrm{L}$ and pick up rate of $80 \%$ are put in the orthogonal experimental scheme to catch out optimized condition (best results).

\subsection{Design of Experiment}

The standard investigational design technique is too complicated to the procedure. 


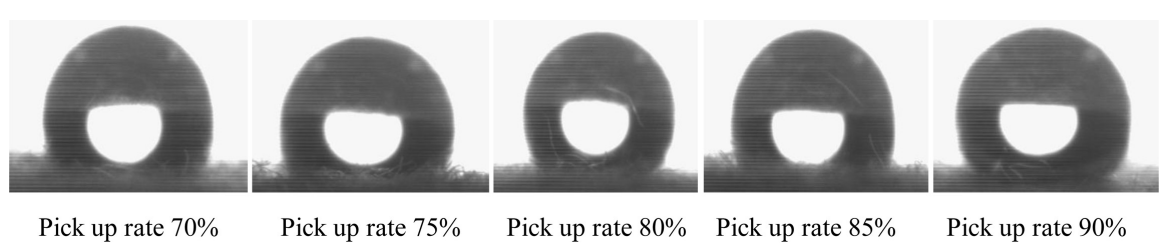

Figure 9. Image of different pick-up rate \% of waterproof treatment of cotton cloth.

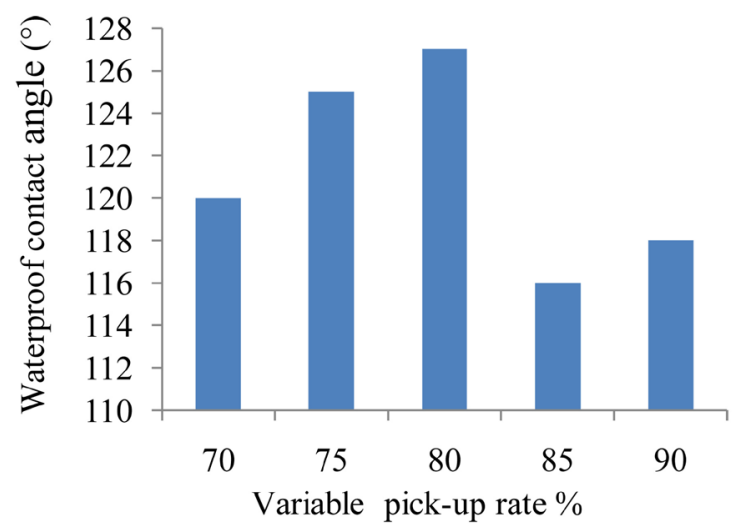

Figure 10. A graphical demonstration of the effect of pick-up rate $\%$ on waterproof cotton cloths and contact angle $\left({ }^{\circ}\right)$.

When the numeral of procedure parameters rises, a vast numeral of investigates must be performed. To explain this difficulty, the Taguchi method ways a specially designed orthogonal array to study the total limit space through only a small amount of experimentation. Three superplastic starting factors are careful to be a controlling factor [14]. Table 7 indicates the superplastic starting factors and the levels are given.

Orthogonal displays are a special standard investigational scheme that needs only a lesser amount of experimental testing to identify the main factors that affect the output. Select the minimum number before the orthogonal array [15]. The experiment to be performed will be determined according to the formula below,

$N$ Taguchi $=1+N V(L-1) ; N$ Taguchi $=$ digit of experiments to be achieved,

$N V=$ digit of parameters; $L=$ digit of levels,

Now this task,

Therefore, $N V=3$ and $L=3$,

So, $N$ Taguchi $=1+4(3-1)=9$.

Therefore, at least 9 experiments are required. Orthogonal array (OA) founded on the selection of experimental turns with at least 9 rows or 9 are nominated [16]. The subsequent regular orthogonal ranges are usually recycled in design investigates:

Levels array: L4, L8, L12, L16, L32,

Levels 3 array: L9, L18, L27 and 4-levels array: L16, L32.

In this work, L9 is enough. This will need a total of 27 investigates to optimize 
Table 7. Indications the factors and the levels.

\begin{tabular}{cccc}
\hline Process parameters & Level 1 & Level 2 & Level 3 \\
\hline Concentration $(\mathrm{g} / \mathrm{L})$ & 10 & 30 & 50 \\
Temperature $\left({ }^{\circ} \mathrm{C}\right)$ & 130 & 150 & 170 \\
Time $(\mathrm{min})$ & 1.5 & 2.0 & 2.5 \\
\hline
\end{tabular}

the factors. The Taguchi investigational design experiment showed an L9 orthogonal range in which 9 experimentations were satisfactory to optimize the parameters. The variables are allocated in the columns identified by the orthogonal range according to the main factors [17]. The last column can be retained wrong, but you should not miss a line. After selecting the orthogonal range, the experiment was selected based on the horizontal combination. It is important to conduct all experiments. Record performance parameters (output) analysis for each experiment run.

\section{Optimum Condition Obtained from the Orthogonal Investigational Scheme}

Allowing to the orthogonal investigational procedure, L9 orthogonal arrays show that, 9 (nine) experiments are enough for estimating optimized conditions. The orthogonal investigate is accepted in the consider, the three-level and four-factors orthogonal investigate is calculated through exchanging the usages of the finishing chemical, curing heat, curing period and pick-up rate of \%, which are stated in Table 8 and Table 9 (orthogonal experimental design of contact angle images and level-factors of waterproof treatment including contact angle degrees).

From the orthogonal experimental Table 9, we find out the optimized concentration for the waterproof finishing (RUNWELL TEO) $30 \mathrm{~g} / \mathrm{L}$, backing temperature $110^{\circ} \mathrm{C}$, pick up rate of $70 \%$ and backing time $1.5 \mathrm{~min}$. The result shows that the optimized waterproof finishing of cotton fabrics is surface of the cotton fibre becomes smooth, the finishing agent has the good film-forming ability, and it takes better waterproof (hydrophobic) performance.

\subsection{Analysis of Oil Repellency Performance}

\subsubsection{Influence of Different Backing Temperature on Cotton Fabric}

The effect of baking temperature on oil repellent finishing chemical RUDOLF CHEMIE (DYMATIC INC) concentration is $30 \mathrm{~g} / \mathrm{L}$, to changing the baking temperature, finishing of cotton cloth according to the finishing process. The oil-repellent hydrocarbon test of the cloth was verified which are stated in Table 10.

According to Table 10 , when the baking temperature is $130^{\circ} \mathrm{C}-150^{\circ} \mathrm{C}$, the oil-repellent treatment of the cotton fabric after finishing is about the hydrocarbon test was suitable grade 6 (n-Decane). The excessive baking temperature, the fibre is damaged. At low-temperature grading is less. Therefore, the test results 
Table 8. Orthogonal experimental design of contact angle images.

\begin{tabular}{|c|c|c|c|}
\hline $\begin{array}{l}\text { Experimental } \\
\text { serial number }\end{array}$ & Waterproof finishing treatment & Image of contact angle & $\begin{array}{l}\text { Contact } \\
\text { angle }\left(^{\circ}\right)\end{array}$ \\
\hline Experiment 1 & $10 \mathrm{~g} / \mathrm{L} ; 110^{\circ} \mathrm{C} ; 1 \mathrm{~min} ; 70 \%$ & & 122 \\
\hline Experiment 2 & $10 \mathrm{~g} / \mathrm{L} ; 130^{\circ} \mathrm{C} ; 1.5 \mathrm{~min} ; 80 \%$ & & 120 \\
\hline Experiment 3 & $10 \mathrm{~g} / \mathrm{L} ; 150^{\circ} \mathrm{C} ; 2 \mathrm{~min} ; 90 \%$ & & 120 \\
\hline Experiment 4 & $30 \mathrm{~g} / \mathrm{L} ; 110^{\circ} \mathrm{C} ; 1.5 \mathrm{~min} ; 90 \%$ & & 130 \\
\hline Experiment 5 & $30 \mathrm{~g} / \mathrm{L} ; 130^{\circ} \mathrm{C} ; 2 \mathrm{~min} ; 70 \%$ & & 120 \\
\hline Experiment 6 & $30 \mathrm{~g} / \mathrm{L} ; 150^{\circ} \mathrm{C} ; 1 \mathrm{~min} ; 80 \%$ & & 120 \\
\hline Experiment 7 & $50 \mathrm{~g} / \mathrm{L} ; 110^{\circ} \mathrm{C} ; 2 \mathrm{~min} ; 80 \%$ & & 110 \\
\hline Experiment 8 & $50 \mathrm{~g} / \mathrm{L} ; 130^{\circ} \mathrm{C} ; 1 \mathrm{~min} ; 90 \%$ & & 105 \\
\hline Experiment 9 & $50 \mathrm{~g} / \mathrm{L} ; 150^{\circ} \mathrm{C} ; 1.5 \mathrm{~min} ; 70 \%$ & & 120 \\
\hline
\end{tabular}

of the oil-repellent (finishing) are taken into consideration. The baking temperature with suitable oil repellent is $140^{\circ} \mathrm{C}$.

\subsubsection{Influence of Different Backing Time on Cotton Fabric}

The effect of baking time on oil repellent chemical RUDOLF CHEMIE (DYMATIC INC) $30 \mathrm{~g} / \mathrm{L}$ finishing liquid, baking temperature $140^{\circ} \mathrm{C}$, changing 
Table 9. Three levels-four factors of waterproof treatment including contact angle degrees.

\begin{tabular}{cccccc}
\hline Factors & $\begin{array}{c}\text { TEO con. } \\
(\mathrm{g} / \mathrm{L})\end{array}$ & $\begin{array}{c}\text { Curing temp } \\
\left({ }^{\circ} \mathrm{C}\right)\end{array}$ & $\begin{array}{c}\text { Curing time } \\
(\mathrm{min})\end{array}$ & Pick up rate $(\%)$ & $\begin{array}{c}\text { Contact } \\
\text { angle }\left({ }^{\circ}\right)\end{array}$ \\
\hline Experiment 1 & 10 & 110 & 1 & 70 & 122 \\
Experiment 2 & 10 & 130 & 1.5 & 80 & 120 \\
Experiment 3 & 10 & 150 & 2 & 90 & 120 \\
Experiment 4 & 30 & 110 & 1.5 & 90 & 130 \\
Experiment 5 & 30 & 130 & 2 & 70 & 120 \\
Experiment 6 & 30 & 150 & 1 & 80 & 120 \\
Experiment 7 & 50 & 110 & 2 & 80 & 110 \\
Experiment 8 & 50 & 130 & 1 & 90 & 105 \\
Experiment 9 & 50 & 150 & 1.5 & 70 & 120 \\
\hline
\end{tabular}

Table 10. Effect of different baking temperature on oil repellent treatment of cotton cloth including grade.

\begin{tabular}{cc}
\hline Treatment & Hydrocarbon test grading \\
\hline $30 \mathrm{~g} / \mathrm{L} ; 130^{\circ} \mathrm{C} ; 1.5 \mathrm{~min} ; 80 \%$ & 4 \\
$30 \mathrm{~g} / \mathrm{L} ; 135^{\circ} \mathrm{C} ; 1.5 \mathrm{~min} ; 80 \%$ & 4 \\
$30 \mathrm{~g} / \mathrm{L} ; 140^{\circ} \mathrm{C} ; 1.5 \mathrm{~min} ; 80 \%$ & 6 \\
$30 \mathrm{~g} / \mathrm{L} ; 145^{\circ} \mathrm{C} ; 1.5 \mathrm{~min} ; 80 \%$ & 6 \\
$30 \mathrm{~g} / \mathrm{L} ; 150^{\circ} \mathrm{C} ; 1.5 \mathrm{~min} ; 80 \%$ & 6 \\
\hline
\end{tabular}

baking time, finishing cotton cloth according to the finishing process. The oil-repellent hydrocarbon test of the cloth was tested which are stated in Table 11.

The baking time is too small, this can be perceived from Table 11 the oil repellent treatment of cotton cloth after finishing the suitable backing time was 2 min (visual test) and oil repellency rating was the biggest 6 (n-Decane). On the other hand, heptane was failed repeatedly because of its poor wetting property.

\subsubsection{Influence of Different Concentration on Cotton Fabric}

The effect of oil repellent finishing chemical concentration on the cotton knitted dyed fabrics oil repellent finishing effect of the fabric. When the baking temperature is $140^{\circ} \mathrm{C}$, and the baking time was $2 \mathrm{~min}$, the concentration of the finishing chemical is changed, and the cotton cloth is finished according to the finishing process. The oil-repellent hydrocarbon test of the cloth was tested which are stated in Table 12.

The oil repellency of the cloth is realized by a film of material with low surface energy adsorbed on the surface of the cloth. The effective component in the 
Table 11. Effect of baking time on oil repellent treatment of cotton cloth with including grade number.

\begin{tabular}{cc}
\hline Treatment & Hydrocarbon test grading \\
\hline $30 \mathrm{~g} / \mathrm{L} ; 140^{\circ} \mathrm{C} ; 0.5 \mathrm{~min} ; 80 \%$ & 6 \\
$30 \mathrm{~g} / \mathrm{L} ; 140^{\circ} \mathrm{C} ; 1 \mathrm{~min} ; 80 \%$ & 6 \\
$30 \mathrm{~g} / \mathrm{L} ; 140^{\circ} \mathrm{C} ; 1.5 \mathrm{~min} ; 80 \%$ & 6 \\
$30 \mathrm{~g} / \mathrm{L} ; 140^{\circ} \mathrm{C} ; 2 \mathrm{~min} ; 80 \%$ & 6 \\
$30 \mathrm{~g} / \mathrm{L} ; 140^{\circ} \mathrm{C} ; 2.5 \mathrm{~min} ; 80 \%$ & 6 \\
\hline
\end{tabular}

Table 12. Effect of different finishing chemical concentration on oil repellent finishing of cotton cloths with including grade number.

\begin{tabular}{cc}
\hline Treatment & Hydrocarbon test grading \\
\hline $20 \mathrm{~g} / \mathrm{L} ; 140^{\circ} \mathrm{C} ; 2 \mathrm{~min} ; 80 \%$ & 4 \\
$25 \mathrm{~g} / \mathrm{L} ; 140^{\circ} \mathrm{C} ; 2 \mathrm{~min} ; 80 \%$ & 4 \\
$30 \mathrm{~g} / \mathrm{L} ; 140^{\circ} \mathrm{C} ; 2 \mathrm{~min} ; 80 \%$ & 4 \\
$35 \mathrm{~g} / \mathrm{L} ; 140^{\circ} \mathrm{C} ; 2 \mathrm{~min} ; 80 \%$ & 6 \\
$40 \mathrm{~g} / \mathrm{L} ; 140^{\circ} \mathrm{C} ; 2 \mathrm{~min} ; 80 \%$ & 6 \\
$45 \mathrm{~g} / \mathrm{L} ; 140^{\circ} \mathrm{C} ; 2 \mathrm{~min} ; 80 \%$ & 6 \\
\hline
\end{tabular}

finishing liquid is an organic fluorine compound, and the arrangement of the organic fluorine molecules on the surface of the fibre decreases the surface tension of the fibre, thereby imparting an oil repellency effect to the fabric. Then, the content of organic fluorine in the finishing liquid determines whether the organic fluorine particles on the surface of the fibre can be carefully aligned, that is, the concentration of the finishing liquid can affect the oil repellency of the cloth subsequently finishing. From Table 12, considering the appropriate concentration of oil repellent chemical $40 \mathrm{~g} / \mathrm{L}$ and oil repellency grade was the biggest 6 (n Decane). Hence all the preferred backing temperature is $140^{\circ} \mathrm{C}$, backing time is $2 \mathrm{~min}$, the concentration of oil repellent chemical $40 \mathrm{~g} / \mathrm{L}$ and hydrocarbon test grading are put in the orthogonal experimental data i.e. find out Optimized condition (best results).

\subsubsection{Optimum Condition Obtained from Orthogonal Experiment (Oil Repellent)}

Nine pieces of each cotton knitted dyed samples are prepared. Allowing to the orthogonal investigational method, show L9 orthogonal ranges, of which 9 experiments are sufficient, optimize parameters. Every sample has a different concentration, different backing temperature, and different backing time. The sample is dipped two times and again padded for two times then weighted. After padding, samples were adjusted according to the experimental sequences. Then the swatches are suspended and dried. After drying, each of the dyed cloth was 
placed in a small dryer and curing machine to maintain the curing time according to the experimental requirements. When the backing treatment is completed, the treated sample was again washed at $60^{\circ} \mathrm{C}$ for $15 \mathrm{~min}$ and then dried at $75^{\circ} \mathrm{C}$ $80^{\circ} \mathrm{C}$. According to different test requirements, the oil repellent treated cotton dyed samples are cut into the different specification for oil repellent hydrocarbon test was tested which is clearly evident from in Table 13.

From the above orthogonal experimental Table 13, we find out the optimized concentration for oil repellent RUDOLF CHEMIE (DYMATIC INC) $35 \mathrm{~g} / \mathrm{L}$; the backing temperature is $150^{\circ} \mathrm{C}$, and backing time $1.5 \mathrm{~min}$, and the grading 6 .

\section{Conclusion}

In this experiment, waterproof and oil repellent behavior of cotton knitted (S/J) cloth was treated with RUNWELL TEO and RUDOLF CHEMIE (DYMATIC INC). Fluorocarbon-free finishing that is applied on cotton knitted single jersey fabrics by two dip-two pad process. Applying waterproof then oil repellent finishing chemicals, the surface of the hydrophobicity of cloth was investigated. When a waterproof finishing chemical RUNWELL TEO was used, then the best waterproofness is obtained by evaluating especially contact angle test, drop test, spray-rating test and the optimized condition is $30 \mathrm{~g} / \mathrm{L}$, backing temperature $110^{\circ} \mathrm{C}$, backing time $1.5 \mathrm{~min}$ and pick up rate $70 \%$. On the other side, oil repellent chemical RUDOLF CHEMIE (DYMATIC INC) was used, then the best oil repellency is obtained by evaluating hydrocarbon test (a visual test) and then the optimized condition was-concentration $35 \mathrm{~g} / \mathrm{L}$, backing temperature $150^{\circ} \mathrm{C}$, backing time 1.5 minutes, pick up-rate $80 \%$. Finally, a sample was treated with an optimized waterproof solution to find out the optimized contact angle and again this waterproof fabric was treated with an oil repellent solution to evaluate hydrophobicity by hydrocarbon test (Visual test) grading. The finishing agent has the function of changing the surface properties of the fiber, so that the surface of the fiber could be modified from hydrophilic to hydrophobic.

Table 13. Three levels-three factors of oil repellent treatment including grade number.

\begin{tabular}{lcccc}
\hline Serial number & $\begin{array}{c}\text { Dynamic con. } \\
(\mathrm{g} / \mathrm{L})\end{array}$ & Temperature $\left({ }^{\circ} \mathrm{C}\right)$ & Time/min & $\begin{array}{c}\text { Hydrocarbon test } \\
\text { grading }\end{array}$ \\
\hline Experiment 1 & 35 & 130 & 1.5 & 4 \\
Experiment 2 & 35 & 140 & 2 & 4 \\
Experiment 3 & 35 & 150 & 2.5 & 6 \\
Experiment 4 & 40 & 130 & 2 & 4 \\
Experiment 5 & 40 & 140 & 2.5 & 4 \\
Experiment 6 & 40 & 150 & 1.5 & 6 \\
Experiment 7 & 45 & 130 & 2.5 & 6 \\
Experiment 8 & 45 & 140 & 1.5 & 4 \\
Experiment 9 & 45 & 150 & 2 & 6 \\
\hline
\end{tabular}




\section{Conflicts of Interest}

The authors declare no conflicts of interest regarding the publication of this paper.

\section{References}

[1] Gulati, A. and Turner, A.J. (1929) 1-A Note on the Early History of Cotton. Journal of the Textile Institute Transactions, 20, T1-T9. https://doi.org/10.1080/19447022908661470

[2] Rowell, R. (2008) Natural Fibres: Types and Properties, in Properties and Performance of Natural-Fibre Composites. Elsevier, Amsterdam, 3-66. https://doi.org/10.1533/9781845694593.1.3

[3] Zhang, M., Atkinson, K.R. and Baughman, R.H. (2004) Multifunctional Carbon Nanotube Yarns by Downsizing an Ancient Technology. Science, 306, 1358-1361. https://doi.org/10.1126/science.1104276

[4] Biagiotti, J., Puglia, D. and Kenny, J.M. (2004) A Review on Natural Fibre-Based Composites-Part I: Structure, Processing and Properties of Vegetable Fibres. Journal of Natural Fibers, 1, 37-68. https://doi.org/10.1300/J395v01n02 04

[5] Siqueira, G., Bras, J. and Dufresne, A. (2010) Cellulosic Bionanocomposites: A Review of Preparation, Properties and Applications. Polymers, 2, 728-765. https://doi.org/10.3390/polym2040728

[6] Basra, A.S. and Malik, C. (1984) Development of the Cotton Fiber. International Review of Cytology, 89, 65-113. https://doi.org/10.1016/S0074-7696(08)61300-5

[7] Norkrans, B. (1968) Cellulose and Cellulolysis. In: Advances in Applied Microbiology, Elsevier, Amsterdam, 91-130. https://doi.org/10.1016/S0065-2164(08)70526-4

[8] Cho, H.M., Gross, A.S. and Chu, J.-W. (2011) Dissecting Force Interactions in Cellulose Deconstruction Reveals the Required Solvent Versatility for Overcoming Biomass Recalcitrance. Journal of the American Chemical Society, 133, 14033-14041. https://doi.org/10.1021/ja2046155

[9] Bhuiyan, M.A.R., Islam, A., Islam, S., et al. (2017) Improving Dyeability and Antibacterial Activity of Lawsonia inermis L on Jute Fabrics by Chitosan Pretreatment. Textiles and Clothing Sustainability, 3, 1. https://doi.org/10.1186/s40689-016-0023-4

[10] McCann, E. and Fal'ko, V.I. (2006) Landau-Level Degeneracy and Quantum Hall Effect in a Graphite Bilayer. Physical Review Letters, 96, Article ID: 086805. https://doi.org/10.1103/PhysRevLett.96.086805

[11] Sobczyk-Guzenda, A., Szymanowski, H., Jakubowski, W., et al. (2013) Morphology, Photocleaning and Water Wetting Properties of Cotton Fabrics, Modified with Titanium Dioxide Coatings Synthesized with Plasma Enhanced Chemical Vapor Deposition Technique. Surface and Coatings Technology, 217, 51-57. https://doi.org/10.1016/j.surfcoat.2012.11.071

[12] Rosen, M.J. and Kunjappu, J.T. (2012) Surfactants and Interfacial Phenomena. John Wiley \& Sons, Hoboken. https://doi.org/10.1002/9781118228920

[13] Holdich, R.G., Dragosavac, M.M., Vladisavljević, G.T., et al. (2012) Continuous Membrane Emulsification with Pulsed (Oscillatory) Flow. Industrial \& Engineering Chemistry Research, 52, 507-515. https://doi.org/10.1021/ie3020457

[14] Dargahi, M., Kazemian, H., Soltanieh, M., et al. (2012) High Temperature Synthesis of SAPO-34: Applying an L9 Taguchi Orthogonal Design to Investigate the Effects 
of Experimental Parameters. Powder Technology, 217, 223-230.

https://doi.org/10.1016/j.powtec.2011.10.030

[15] Muhammad, S.A., Ahmed, S., Ismail, T., et al. (2014) Taguchi's Experimental Design for Optimizing the Production of Novel Thermostable Polypeptide Antibiotic from Geobacillus pallidus SAT4. Pakistan Journal of Pharmaceutical Sciences, 27, 11-23.

[16] Mahmoud, T. and Ahmed, B.S. (2015) An Efficient Strategy for Covering Array Construction with Fuzzy Logic-Based Adaptive Swarm Optimization for Software Testing Use. Expert Systems with Applications, 42, 8753-8765. https://doi.org/10.1016/j.eswa.2015.07.029

[17] Fei, N.C., Mehat, N.M. and Kamaruddin, S. (2013) Practical Applications of Taguchi Method for Optimization of Processing Parameters for Plastic Injection Moulding: A Retrospective Review. ISRN Industrial Engineering, 2013, Article ID: 462174. https://doi.org/10.1155/2013/462174 